\section{P148 CORRELATING CHANGES IN LUNG FUNCTION WITH PATIENT REPORTED OUTCOMES IN COPD}

doi:10.1136/thx.2010.150987.49

${ }^{1} \mathrm{P}$ W Jones, ${ }^{2} \mathrm{~J}$ Donohue, ${ }^{3} \mathrm{~J}$ Nedelman, ${ }^{4} \mathrm{G}$ Pinault, ${ }^{4} \mathrm{~S}$ Pascoe. ${ }^{1}$ Division of Clinical Science, St George's University of London, London, UK; ${ }^{2}$ Division of Pulmonary \& Critical Care, University North Carolina School of Medicine, Chapel Hill, North Carolina, USA; ${ }^{3}$ Novartis Pharmaceuticals Corporation, East Hanover, United States; ${ }^{4}$ Novartis Pharma AG, Basel, Switzerland

Introduction Relationships between improvements in lung function and other outcomes in COPD patients are not documented extensively. We examined the association between changes in $\mathrm{FEV}_{1}$ and patient-centred outcomes using pooled data from three indacaterol studies.

Methods We calculated correlations between changes in Transition Dyspnea Index (TDI) and St. George's Respiratory Questionnaire (SGRQ) scores (at 12, 26 and 52 weeks) and exacerbation frequency (rate/year) across five categories of $\Delta \mathrm{FEV}_{1}$ with boundary points (in mls) between categories: -500 (lowest value), $-50,+50,+150$, $+250,+500$ (highest value), centred at $-275,0,100,200$ and $375 \mathrm{ml}$. We also performed generalised linear modelling adjusting for covariates including baseline severity, treatment and ICS use.

Results 3313 patients with non-missing values of relevant variables were analysed, excluding extreme values of $\Delta \mathrm{FEV}_{1}$ (outside $\pm 500 \mathrm{ml}$ ). TDI and $\Delta$ SGRQ at 12 weeks improved and exacerbation rate declined with increasing positive $\Delta \mathrm{FEV}_{1}$ (all $\mathrm{p}<0.001$ ) (see Abstract P148 Table 1). Individual-level correlations were weak (0.06-0.18), reflecting the large variability in the outcomes, but cohort-level correlations were strong (0.76-0.93). Results for the proportion of patients demonstrating an improvement of at least the minimal clinically important difference (MCID) for TDI and SGRO followed a similar pattern to the meaned data. In general, adjustments for baseline covariates, including level of airway obstruction, had little impact on the relationship between $\Delta \mathrm{FEV}_{1}$ and outcomes.

Conclusions These results suggest that larger improvements in $\mathrm{FEV}_{1}$ with long-acting bronchodilator therapy are likely to be associated with larger patient-centred benefits across a range of outcomes.

Abstract P148 Table 1 Mean outcomes by average $\Delta \mathrm{FEV}_{1}$ category

\begin{tabular}{llll}
\hline $\begin{array}{l}\text { Category } \\
\text { centred value } \\
\text { of } \Delta \text { FEV }_{\mathbf{1}}(\mathbf{m l})\end{array}$ & TDI $(\mathbf{n}=\mathbf{2 7 8 1})$ & $\mathbf{\Delta S G R O}(\mathbf{n}=\mathbf{3 1 4 1})$ & $\begin{array}{l}\text { Exacerbation } \\
\text { rate/year }(\mathbf{n}=\mathbf{3 1 5 8})\end{array}$ \\
\hline-275 & 1.44 & -3.15 & 0.63 \\
0 & 1.31 & -3.17 & 0.58 \\
100 & 1.79 & -3.84 & 0.61 \\
200 & 2.12 & -5.84 & 0.51 \\
375 & 2.68 & -7.38 & 0.38
\end{tabular}

\section{P149 VALIDATION OF THE COPD ASSESSMENT TEST (CAT) WITHIN $\alpha-1$ ANTITRYPSIN DEFICIENCY (A1ATD)}

doi:10.1136/thx.2010.150987.50

R G Edgar, D Griffiths, R A Stockley. University Hospitals Birmingham, Birmingham, UK

Introduction and objectives The COPD Assessment Test (CAT) has recently been validated with a USA cohort as a health status questionnaire (HSO) for use in chronic obstructive pulmonary disease (COPD). ${ }^{1}$ Its purpose is to guide and improve communication between the health care professional and patient and identify key areas for health improvement. Historically, other HSQ have been used in COPD especially the St Georges Respiratory Questionnaire (SGRQ) which has been extensively validated for use in clinical care and trials. However the SGRQ has a complex scoring algorithm and requires several minutes to complete restricting its use in daily clinical practice. ${ }^{2}$ The CAT was developed as a user friendly, time efficient, easily analysed and reliable HSO for COPD. We have an extensive database for patients with $\boldsymbol{\alpha}-1$ Antitrypsin Deficiency (A1ATD) and have an annual review at which the SGRO is used. We wished to compare CAT with the SGRO in these patients.

Methods 163 consecutive patients with A1ATD attending the Antitrypsin Deficiency Assessment and Programme for Treatment (ADAPT) centre were asked to complete both SGRO and CAT prior to full Lung function and medical review. All patients were clinically stable (at least 6 weeks post exacerbation). SGRO and CAT scores were compared as well as routine post bronchodilator lung function parameters to determine the relationships.

Results 157 patients completed both questionnaires. CAT correlated strongly with SGRQ total score $\left(R^{2}=0.799, p<0.0001, n=157\right)$ (Abstract P149 Figure 1) and its domains (impact $\mathrm{R}^{2}=0.751$, symptoms $\mathrm{R}^{2}=0.59$ and activity $\left.\mathrm{R}^{2}=0.66\right)$. CAT values also correlated with lung function including $\mathrm{FEV}_{1} \%$ predicted $\left(\mathrm{R}^{2}=0.26\right.$, $\mathrm{p}<0.0001, \mathrm{n}=157), \mathrm{FEV}_{1} / \mathrm{FVC}\left(\mathrm{R}^{2}=0.224, \mathrm{p}<0.0001, \mathrm{n}=157\right), \mathrm{KCO}$ \%predicted $\left(\mathrm{R}^{2}=0.151, \mathrm{p}<0.0001, \mathrm{n}=147\right)$ all of which were comparable to those seen with SGRO.

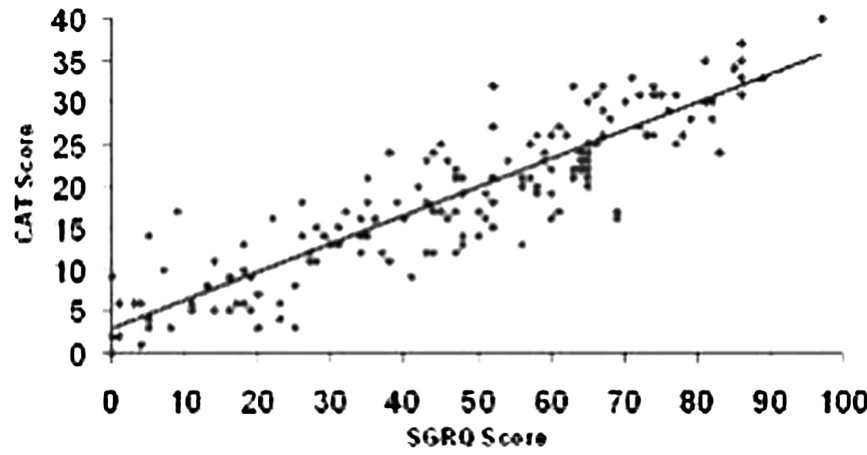

Abstract P149 Figure 1

Conclusion CAT offers a short $\mathrm{HSO}$ that is simple to use and analyse, correlates well with the more complex SGRQ and stable lung function.

\section{REFERENCES}

1. Jones PW, Harding G, Berry $\mathrm{P}$, et al. Development and first validation of the COPD Assessment Test. Eur Respir J 2009;34:648-54.

2. Glaab T, Vogelmeier C, Buhl R. Outcome measures in chronic obstructive pulmonary disease (COPD): strengths and limitations. Respir Res 2010:11:79. 